\title{
New Treatment Options in COPD
}

\author{
DANIEL E. HILLEMAN, PharmD
}

\begin{abstract}
OBJECTIVE: To review the role of long-acting bronchodilators in the treatment of chronic obstructive pulmonary disease (COPD), including the importance of treatment adherence.

SUMMARY: Overall, clinical trials show that compared with placebo and ipratropium, tiotropium significantly improves spirometric measures, increases quality-of-life scores, and is associated with fewer exacerbations. In addition, compared with salmeterol, tiotropium is associated with greater improvements in spirometric measures and clinically meaningful increases in quality-of-life measures. In comparison with either fluticasone or salmeterol alone, the fluticasone/salmeterol combination is associated with statistically greater improvement in spirometric and dyspnea measures; however, the combination is not associated with fewer exacerbations than either fluticasone or salmeterol used by itself.

CONCLUSIONS: The 2003 update to the Global Initiative for Chronic Obstructive Lung Disease (GOLD) guidelines recommends regular treatment with long-acting bronchodilators for maintenance COPD therapy because of superior effectiveness and convenience compared with short-acting bronchodilators. The results from trials presented in this article demonstrate that inhaled tiotropium is effective in treating COPD and might be considered as a first-line agent for maintenance therapy in view of its outcomes data. The convenience of once-daily administration would probably contribute to patient adherence and thus to the overall efficacy of this agent.
\end{abstract}

KEYWORDS: Chronic obstructive pulmonary disease (COPD); Lung diseases, obstructive; Bronchodilators; Tiotropium; Fluticasone; Salmeterol; Corticosteroid

J Manag Care Pharm. 2005;11(6)(suppl S-a):S12-S19

\section{Author}

DANIEL E. HILLEMAN, PharmD, is a professor of medicine and pharmacy practice, Creighton University School of Pharmacy and Creighton Cardiac Center, both in Omaha, Nebraska.

AUTHOR CORRESPONDENCE: Daniel E. Hilleman, PharmD, Professor of Pharmacy Practice, Creighton University School of Pharmacy, 2500 California St., Omaha, NE 68178. Tel: (402) 280-4220; Fax: (402) 280-4288;

E-mail:hilleman@creighton.edu

Copyright $\odot$ 2005, Academy of Managed Care Pharmacy. All rights reserved. $\square$ hronic obstructive pulmonary disease (COPD) is characterized by a great reduction in expiratory airflow, chronic cough, and dyspnea. ${ }^{1}$ Improved airflow and reduced breathlessness are important treatment outcomes in COPD. Maintenance treatment with bronchodilators, including $\beta$-agonists, anticholinergic agents, and theophylline, has been the standard of care for COPD, since these agents treat the bronchoconstriction associated with COPD. ${ }^{2}$ Specifically, ipratropium bromide, an inhaled anticholinergic agent, emerged in the 1970s as a safe and effective treatment for COPD, but its effectiveness may be limited by a frequent (up to 4 times daily) dosing schedule. ${ }^{1,3,4}$ Several other agents with a once- or twice-daily dosing schedule have now been approved for COPD. Recently, 2 inhaled, long-acting bronchodilators from different pharmacologic classes, the oncedaily anticholinergic tiotropium (Spiriva, Boehringer Ingelheim/ Pfizer) and the twice-daily steroid/bronchodilator fluticasone/ salmeterol (Advair, GlaxoSmithKline) have demonstrated efficacy and safety in treating COPD., ${ }^{2,3}$ These agents differ, however, in outcomes measures such as quality of life, dyspnea, spirometric measures, and COPD exacerbations. This article will discuss the outcomes of several pivotal clinical trials that illustrate how these agents differ in the management of COPD.

\section{Long-term Tiotropium Versus Placebo}

\section{Trial Introduction and Method}

Casaburi and colleagues evaluated the effects of tiotropium in 2 identical randomized, double-blind, placebo-controlled 1-year studies involving 921 patients from 50 clinical centers in the United States. ${ }^{3}$ Patients inhaled tiotropium $18 \mu \mathrm{g}(\mathrm{N}=550)$ or placebo $(\mathrm{N}=371)$ once daily as a dry powder. Medication use and adverse events were recorded. Previous treatment with shortacting $\beta$-agonists, theophylline, or steroids was accepted as long as the therapy was relatively stable. Primary outcomes were based on spirometry, quality of life, and exacerbations: the primary spirometric outcome was trough forced expiratory volume in 1 second ( $\mathrm{FEV}_{1}$; i.e., $\mathrm{FEV}$ prior to dosing), changes in dyspnea were measured using the Transition Dyspnea Index (TDI), and health status was measured by the disease-specific St. George's Respiratory Questionnaire (SGRQ) and the generic Short Form 36 (SF36).

\section{Results}

Overall, patients taking tiotropium showed statistically significant improvements in $\mathrm{FEV}_{1}$ /forced vital capacity (FVC), peak expiratory flow rate (PEFR), TDI, and SGRQ/SF36 scores compared with patients who were receiving placebo. Specifically, during the 1-year study, tiotropium provided significantly superior bronchodilation for trough $\mathrm{FEV}_{1}$ response $(\sim 12 \%$ over baseline, $P<0.01)$ and mean response during the 3 hours after dosing ( $22 \%$ over baseline, $P<0.001)$. Compared with patients receiving placebo, patients taking tiotropium had less dyspnea $(P<0.001)$, superior 
health status scores, fewer COPD exacerbations (36\% vs. $42 \%$, $P<0.05)$, fewer hospitalizations (5.5\% vs. $9.4 \%, P<0.05)$, and fewer hospital days (0.6 days/year vs. 1.2 days/year, $P=0.023$ ). A similar percentage of patients in the tiotropium and placebo groups experienced adverse events during the 1-year study, with $9.6 \%$ patients receiving tiotropium and $13.7 \%$ receiving placebo who dropped out of the study as a result. Dry mouth was the only adverse reaction that was significantly more frequent in patients receiving tiotropium (16\%) than in those receiving placebo $(2.7 \%)$. In most cases, the dry mouth was reported to be mild and $<1 \%$ of the patients withdrew because of it. There were no significant differences between the groups in the percentage of patients with serious adverse events, in those withdrawing due to adverse events, or in deaths during the study. ${ }^{3}$

\section{- Tiotropium Versus Ipratropium}

\section{Trial Introduction and Method}

In 2000, van Noord et al. published a study of 288 patients with COPD, documenting significant improvements in spirometric values over 3 months in patients receiving tiotropium $18 \mu \mathrm{g}$ once daily compared with ipratropium $40 \mu \mathrm{g} 4$ times daily. ${ }^{5}$ These patients continued on to a 1-year randomized, double-blind trial, and the results were combined with those of a second large multicenter 1-year trial. ${ }^{6}$ Both studies incorporated a randomized double-blind, parallel-group design. From 29 clinical centers in the Netherlands and Belgium, 356 patients with COPD were randomized to tiotropium $18 \mu \mathrm{g}$ once daily in the morning (from a metered dose inhaler [MDI]) while 179 patients were randomized to ipratropium $40 \mu \mathrm{g} 4$ times daily. Patients in both studies were permitted albuterol MDIs as needed for acute symptom relief, but bronchodilators other than study drugs were not permitted. Outcome criteria included lung function by spirometry, dyspnea frequency, exacerbation rate, and health-related qualityof-life (HRQOL) scores.

\section{Results}

Patients receiving tiotropium showed significant improvement in spirometry measures, with a mean $\mathrm{FEV}_{1}$ of $1.25 \pm 0.43 \mathrm{~L}(41.9 \pm$ $12.7 \%$ of the predicted value) compared with $1.18 \pm 0.37 \mathrm{~L}(39.4$ $\pm 10.7 \%$ of the predicted value) in patients receiving ipratropium. Trough $\mathrm{FEV}_{1}$ measurements at 1 year improved by $0.12 \pm 0.01 \mathrm{~L}$ with tiotropium, but declined by $0.03 \pm 0.02 \mathrm{~L}$ with ipratropium $(P<0.001){ }^{6}$

Exacerbations and hospitalizations were less frequent in the tiotropium group. The percentage of patients experiencing one or more exacerbations during the 1-year treatment period was significantly lower in the tiotropium group than in the ipratropium group ( $35 \%$ vs. $46 \%$, respectively, $P=0.014$ ). The frequency of exacerbations/patient/year was $24 \%$ lower for patients taking tiotropium $(P=0.006)$. In addition, the number of exacerbation days/patient/year was $39 \%$ lower in the tiotropium group (10.8 vs. $17.7, P=0.002$ ). The first exacerbations occurred significantly later

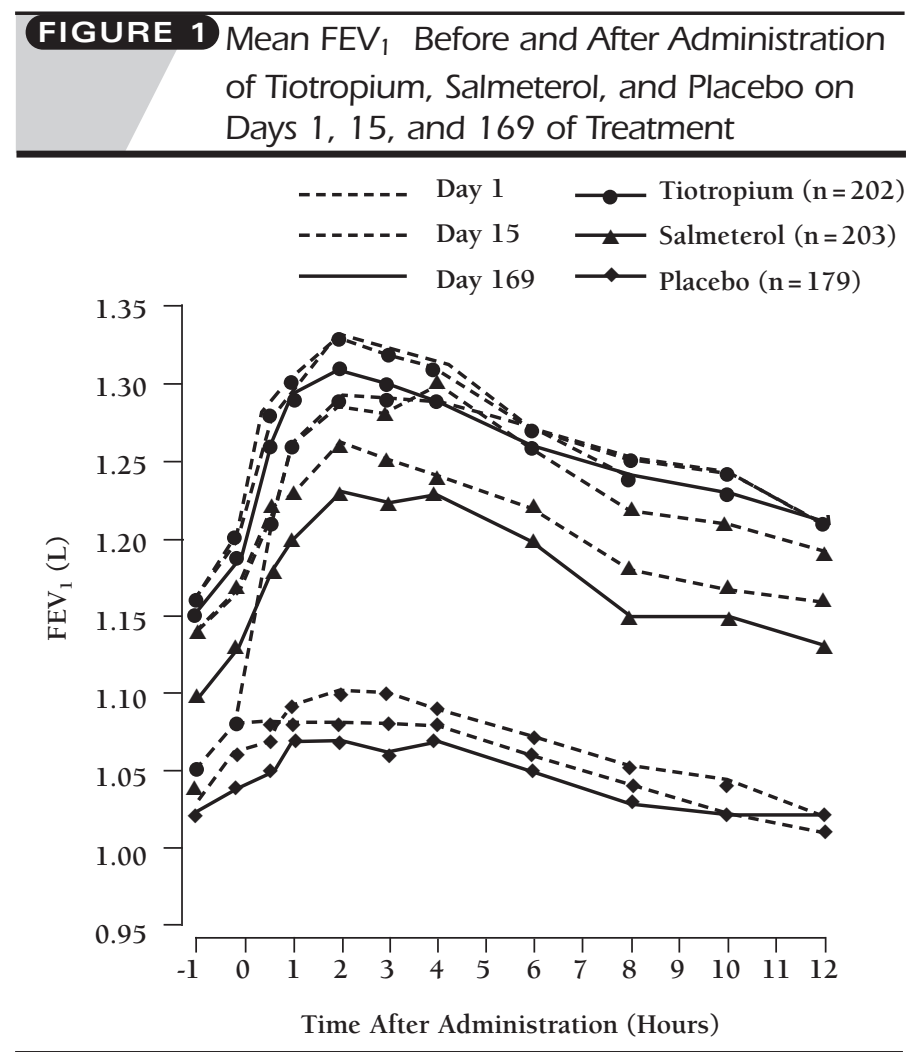

$P<0.001$ for tiotropium versus placebo on all test days posttreatment; $P<0.05$ for tiotropium versus salmeterol on all test days except day 1 and -1 hour on day 15. $\mathrm{FEV}_{1}=$ forced expiratory volume in 1 second.

in patients receiving tiotropium $(P=0.008)$. Hospitalizations due to COPD exacerbations during the 1-year treatment period showed a similar pattern, with a total of $7.3 \%$ of patients hospitalized in the tiotropium group and $11.7 \%$ in the ipratropium group $(P=0.11)$. The number of hospitalizations/patient/year for a COPD exacerbation was 38\% lower in the tiotropium group (0.10 vs. $0.16, P=0.08$ ), while the number of hospitalization days/patient/year was 33\% lower in patients receiving tiotropium (1.42 vs. $2.13, P=0.09$ ). Furthermore, the time to first hospitalization due to a COPD exacerbation was significantly longer in the tiotropium group than in the ipratropium group $(P=0.048)$. On average, patients in the tiotropium group had approximately 4 fewer albuterol inhalations per week than patients who were receiving ipratropium $\left(P<0.05\right.$ for 40 of the 52 weeks). ${ }^{6}$

There was no statistically significant difference in the number of patients in each treatment group who withdrew from the study because of adverse side effects. Dry mouth was the only adverse effect classified as drug-related; it was reported by $14.7 \%$ of patients in the tiotropium group and $10.3 \%$ of patients in the ipratropium group. None of the patients in the study withdrew because of dry mouth. ${ }^{6}$ 
FIGURE 2 SGRO Total Score at Baseline and at Days 57 , 113, and 169 for the Tiotropium, Salmeterol, and Placebo Groups

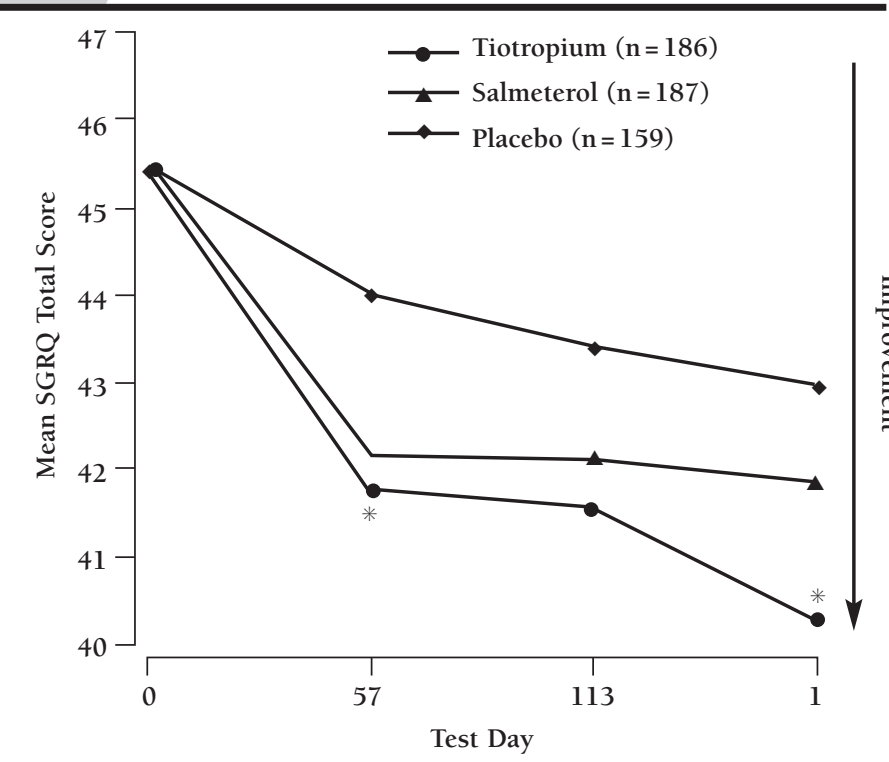

* $P<0.05$ for tiotropium versus placebo at day 57 and day 169. Salmeterol and tiotropium versus placebo are not statistically significant. ${ }^{7}$ $S G R Q=S t$. George's Respiratory Questionnaire.

FIGURE 3 Change in SGRO Total and Impacts Scores From Baseline to Day 169 for the Tiotropium, Salmeterol, and Placebo Groups

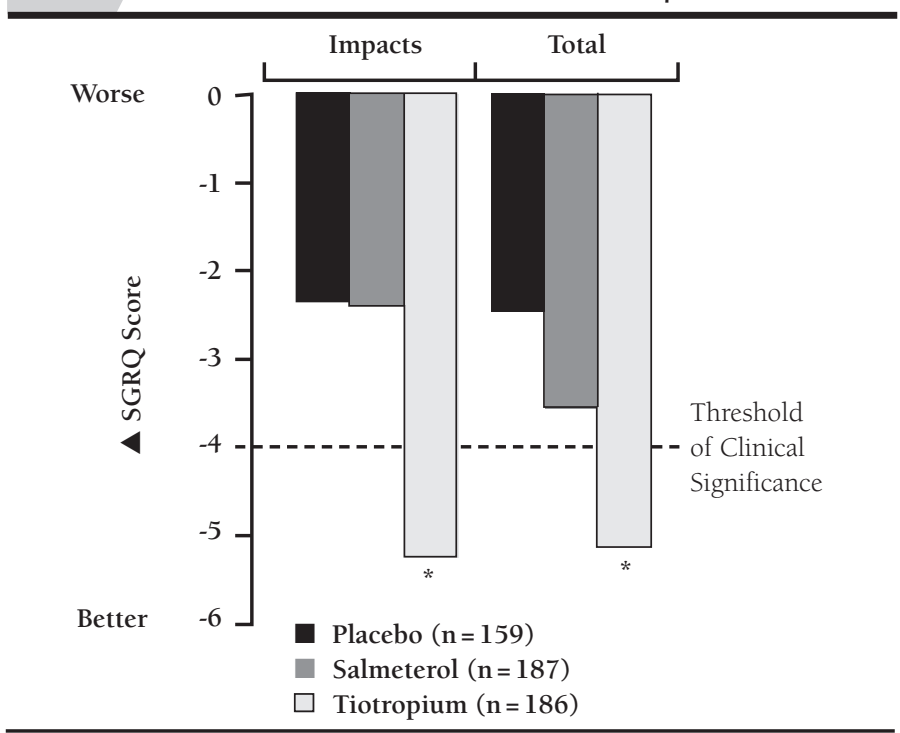

* $P<0.05$ for tiotropium versus placebo. Salmeterol versus placebo and tiotropium versus salmeterol are not statistically significant. ${ }^{7}$

$S G R Q=S t$. George's Respiratory Questionnaire.

\section{Tiotropium Versus Salmeterol}

The comparative efficacy of tiotropium and salmeterol in the treatment of COPD was compared in 2 recent 6-month, randomized clinical trials. ${ }^{7,8}$

\section{Tiotropium Versus Salmeterol Trial 17 \\ Trial Introduction and Method}

This was a 6-month, randomized, placebo-controlled, doubleblind, double-dummy, parallel-group comparison of tiotropium, $18 \mu \mathrm{g}$ once daily via dry-powder inhaler, and salmeterol, $50 \mu \mathrm{g}$ twice daily via MDI. Efficacy was assessed by 12 -hour monitoring of spirometry, TDI, and the SGRQ HRQOL measure. A total of 623 patients were included: 209 receiving tiotropium, 213 receiving salmeterol, and 201 receiving placebo.

\section{Results}

As shown in Figure 1, tiotropium was associated with significantly greater improvement of $\mathrm{FEV}_{1}$ than salmeterol on day 15 and at the end of treatment (day 169) $(P<0.05)$. Both active compounds had a significantly greater effect than placebo on FVC values, but tiotropium was superior to salmeterol for trough FVC and peak FVC measurements. At the end of the study, mean trough FVC in the patients receiving tiotropium was $112 \mathrm{~mL}(P<0.01)$ higher than in the patients receiving salmeterol. As with $\mathrm{FEV}_{1}$, the differences in TDI focal scores between tiotropium and salmeterol appeared to increase over time.

Despite the similarity of objective measurements, the patients receiving tiotropium were significantly more likely than those receiving salmeterol to consider that the treatment had improved their clinical condition (Figure 2). In the SGRQ test, a decrease of 4 units or more is associated with clinical improvement. The difference is demonstrated dramatically by the comparison of SGRQ total and impacts scores in Figure 3.

Patients used a mean 2.65 puffs/day of albuterol during the baseline run-in period. Their mean weekly requirement for albuterol, in comparison with the placebo group, underwent an equal decrease with tiotropium (-1.45 puffs per day) and salmeterol ( -1.44 puffs per day). This represented a statistically significant $(P<0.0001)$ decrease in albuterol use for both tiotropium and salmeterol groups.

A larger percentage of patients left the trial in the salmeterol (13.6\%) and placebo groups (19.4\%) due to adverse events compared with $5.7 \%$ in the tiotropium group $(P<0.001)$. Somewhat fewer patients left the study because of exacerbations of COPD $(36.8 \%$ vs. $38.5 \%)$, but the difference was not statistically significant. The most common adverse event related to tiotropium treatment was dry mouth (10\%), which did not cause any of the participants to leave the study. Other than dry mouth, there were no significant differences in the incidence of adverse events among the treatment groups. 


\section{Tiotropium Versus Salmeterol Trial 28 Trial Introduction and Method}

A second 6-month trial that employed a similar design to the Donohue study compared treatment outcomes in 402 patients receiving tiotropium, 405 patients receiving salmeterol, and 400 patients receiving a matching placebo. ${ }^{8}$ The study results were combined for comparison of exacerbations, health resource use, dyspnea (assessed by the transitional dyspnea index, TDI), HRQOL (assessed by SGRQ), and spirometry.

\section{Results}

As shown in Figure 4, both tiotropium and salmeterol showed equal efficacy after the first doses in improving trough, peak, and mean $\mathrm{FEV}_{1}$, but by day 15, tiotropium showed a statistically greater effect than salmeterol on these measures. Compared with placebo, the mean improvement in trough $\mathrm{FEV}_{1}$ for tiotropium and salmeterol was $0.12 \mathrm{~L}$ and $0.09 \mathrm{~L}$, respectively $(P<0.01$ for either active treatment compared with placebo; $P<0.05$ tiotropium versus salmeterol), on the last day of the study. Tiotropium was statistically superior to salmeterol in modifying peak $\mathrm{FEV}_{1}$ and the area under the curve from 0 to 3 hours in combined and individual studies. Similarly, trough $\mathrm{FEV}_{1}$ values were improved to a statistically significant degree in patients who received tiotropium in one of the individual studies, and this finding was carried over when the study results were combined. At the conclusion of the study (day 169), patients receiving tiotropium showed significant improvement in lung function compared with patients receiving salmeterol or placebo. These results were nearly identical to those seen by Donohue et al. ${ }^{7}$

Figure 5 shows that compared with placebo, tiotropium significantly delayed the time to the first COPD exacerbation $(P<0.01)$, which is significant considering the short trial period. The percentage of patients with at least one exacerbation was 32\%, $35 \%$, and $39 \%$ in the tiotropium, salmeterol, and placebo groups, respectively $(P>0.05)$. Patients who received tiotropium had significantly fewer COPD exacerbations per patient year (1.07; $P>0.05)$ than those who received salmeterol (1.23) or placebo (1.49). The difference between salmeterol and placebo was not significant.

Three studies have examined the fixed-dose combination of fluticasone and salmeterol versus each individual component and placebo. These studies are described below.

\section{Fluticasone/Salmeterol Versus Placebo}

\section{Trial Introduction and Method}

Mahler et al. conducted a randomized, double-blind, placebocontrolled trial comparing the effects of combination therapy with fluticasone/salmeterol and each of these agents alone in patients with COPD. ${ }^{2}$ The 4 treatment groups consisted of patients receiving placebo $(\mathrm{N}=181)$, salmeterol $50 \mu \mathrm{g}(\mathrm{N}=160)$, fluticasone $500 \mu \mathrm{g}$ ( $\mathrm{N}=168)$, or fluticasone/salmeterol $500 \mu \mathrm{g} / 50 \mu \mathrm{g}(\mathrm{N}=165)$, each administered twice daily for a total of 24 weeks. Treatment

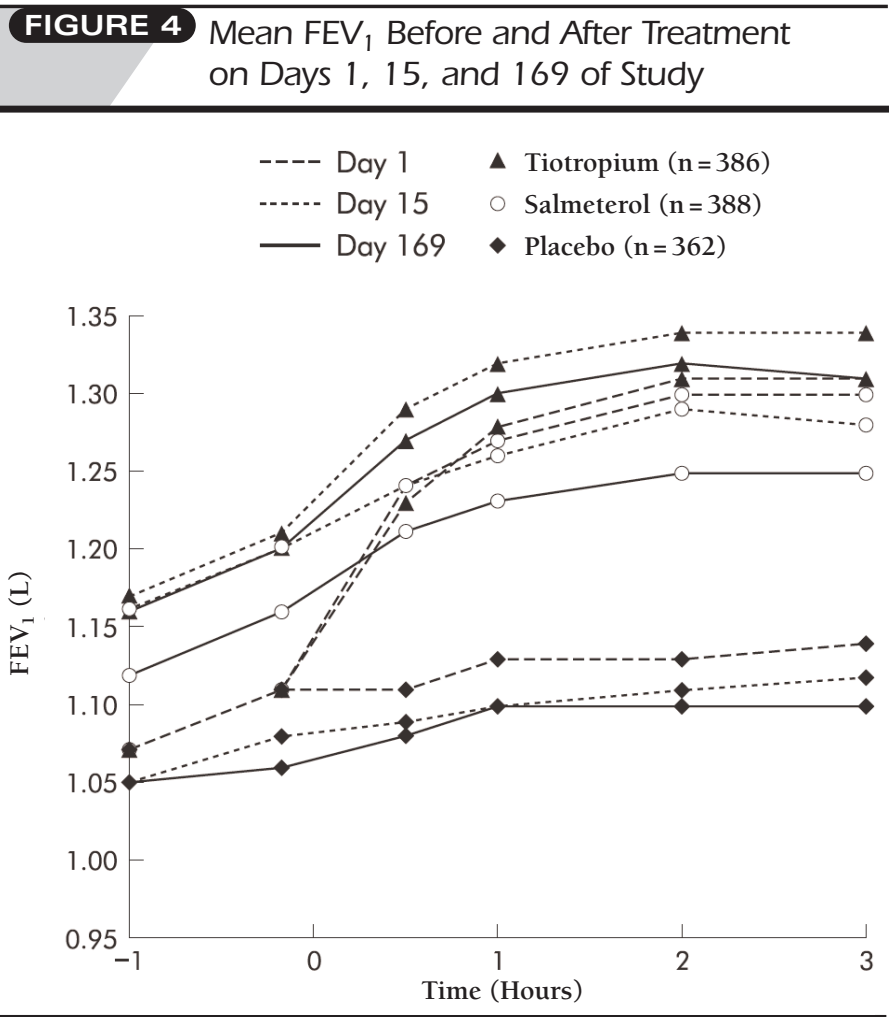

$P<0.001$ for tiotropium versus placebo on all test days after treatment; $P<0.05$ for tiotropium versus salmeterol on all test days except day 1 and -1 hour on day 15.8. $F E V_{1}=$ forced expiratory volume in 1 second.

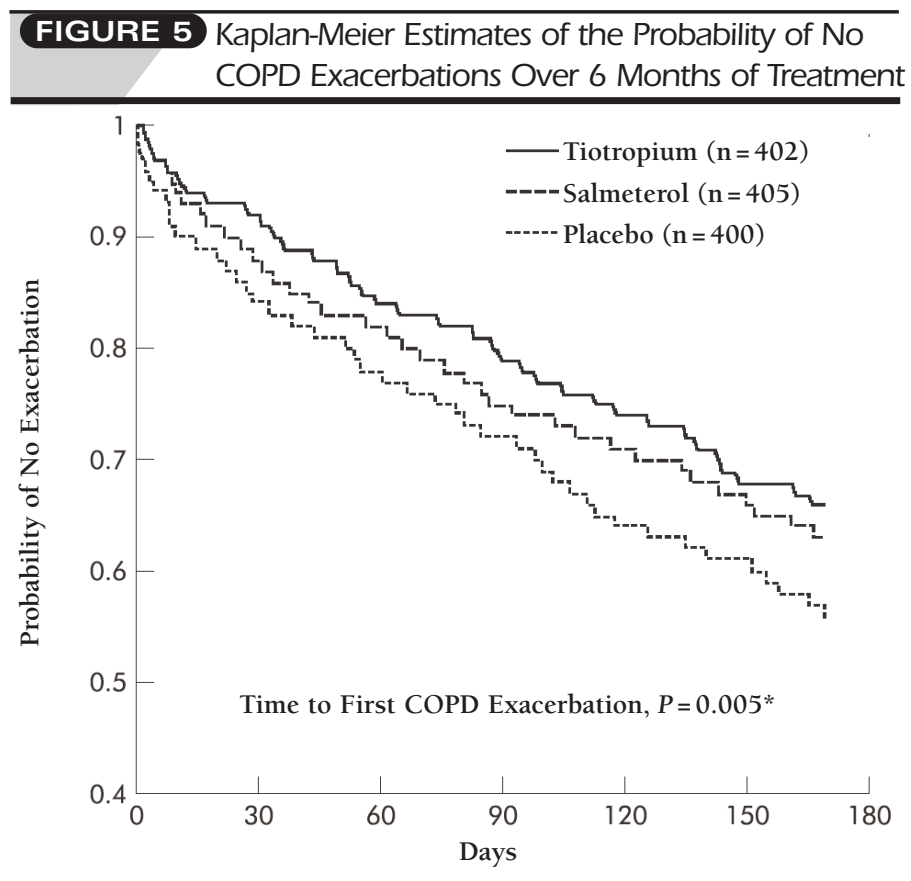

* $\mathrm{P}=0.005$ for tiotropium versus placebo (log rank test). $\mathrm{COPD}=$ chronic obstructive pulmonary disease. 
(TABLE 1$)$ Estimated Treatment Differences

in Efficacy Parameters at End Point ${ }^{2}$

\begin{tabular}{l|c|c|c|c|c}
\hline & \multicolumn{5}{|c}{ Treatment Group Comparison } \\
\hline Evaluation & FSC vs. P & FSC vs. F & FSC vs. S & F vs. P & S vs. P \\
\hline Predose FEV 1 & $159^{*}$ & $54^{*}$ & $67^{*}$ & $105^{*}$ & $92^{*}$ \\
\hline 2-hour postdose FEV 1 & $231^{*}$ & $129^{*}$ & 40 & $101^{*}$ & $191^{*}$ \\
\hline TDI & $1.7^{*}$ & $0.7^{*}$ & $1.2^{*}$ & $1.0^{*}$ & 0.5 \\
\hline CRDQ & $5.3^{*}$ & $4.8^{*}$ & 1.6 & 0.5 & 3.8 \\
\hline CBSQ & $0.6^{*}$ & 0.4 & 0.2 & 0.2 & 0.3 \\
\hline
\end{tabular}

* $P<0.05$.

$C B S Q=$ Chronic Bronchitis Syndrome Questionnaire; $C R D Q=$ Chronic Respiratory Disease Questionnaire; $F$ =fluticasone propionate; $F E V_{1}=$ forced expiratory volume in 1 second; FSC = fluticasone propionate and salmeterol combined; $P=$ placebo; $S=$ salmeterol; TDI = Transition Dyspnea Index.

outcomes were assessed by $\mathrm{FEV}_{1}$, PEFR, TDI, QOL (Chronic Respiratory Disease Questionnaire and Chronic Bronchitis Symptoms Questionnaire) measures, and exacerbations.

\section{Results}

As shown in Table 1, the patients receiving the combination of fluticasone/salmeterol showed statistically significant improvements in $\mathrm{FEV}_{1}$, TDI, and both QOL measures in comparison with patients receiving placebo. The combination exhibited clinical superiority over fluticasone, while the results were less clear when it was compared with salmeterol. More specifically, the patients treated with fluticasone/salmeterol showed a significant improvement in TDI, while their QOL scales were not significantly different from those of the salmeterol group. Both active compounds administered alone were more effective than placebo in improving spirometric measurements but not in improving symptoms.

Candidiasis was the only adverse event reported in more patients taking either fluticasone or fluticasone/salmeterol.

No statistically significant differences in time to exacerbation were noted among the treatment groups. However, there was significant reduction in overall albuterol use (i.e., number of inhalations per day and percentage of days without albuterol use) in patients receiving the combination compared with those receiving fluticasone. Significant reductions in albuterol use were also observed in the salmeterol and fluticasone treatment groups. Subjects in all 3 active treatment groups reported significantly more nights with no awakenings during which they used albuterol $(P<0.001)$.

\section{Trial of Inhaled Steroids and Long-Acting} $\beta$-2 Agonists (TRISTAN)

\section{Trial Introduction and Method}

The TRISTAN trial was a randomized, double-blind, placebocontrolled 52-week parallel trial of salmeterol $50 \mu \mathrm{g}$ twice daily ( $\mathrm{N}=372$ ), fluticasone $500 \mu \mathrm{g}$ twice daily $(\mathrm{N}=374)$, fluticasone/ salmeterol (FSC) 50/500 $\mathrm{gg}$ twice daily $(\mathrm{N}=358)$, and placebo
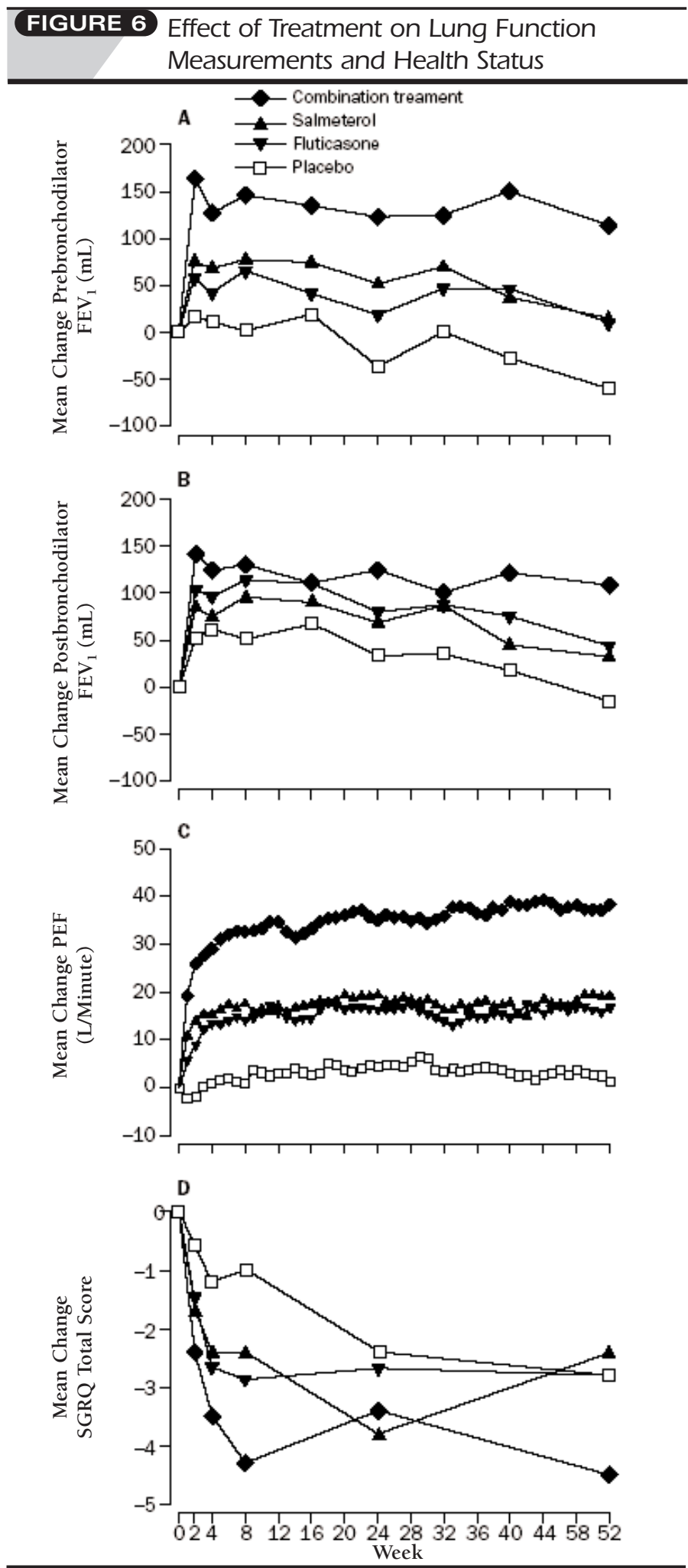

Raw mean changes from baseline are shown: A. Prebronchodilator FEV1; B. Postbronchodilator $\mathrm{FEV}_{1}$; C. Daily peak expiratory flow; D. Health status - the fall in St George's score represents an improvement in health status. ${ }^{8,9} \mathrm{FEV}=$ forced expiratory volume in 1 second; $P E F=$ peak expiratory flow; $S G R Q=S$. George's Respiratory Questionnaire. 


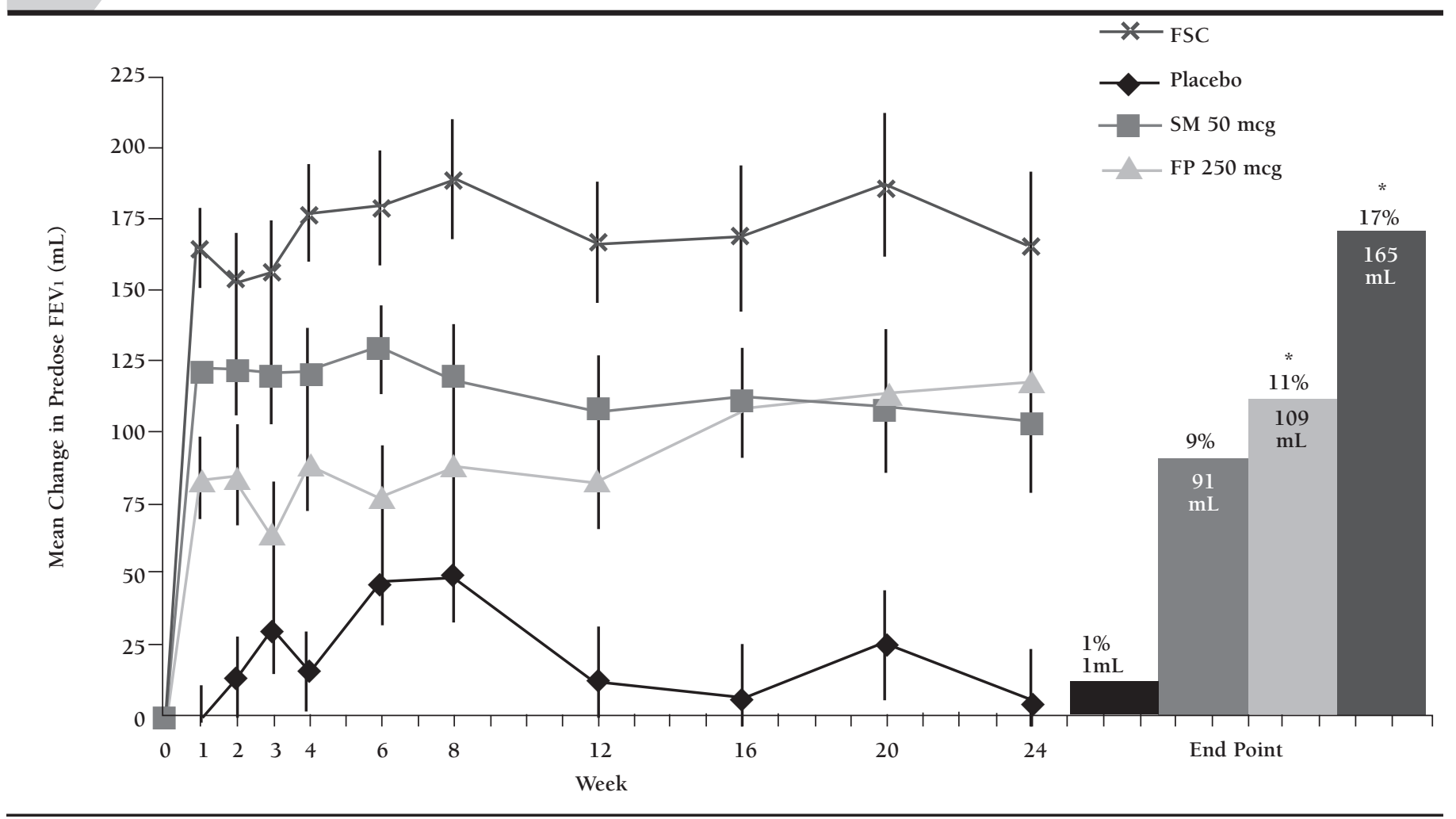

* $P<0.001$, fluticasone/salmeterol combination (FSC) versus placebo; $P=0.012$, FSC versus salmeterol (SM); $P<0.001$, fluticasone (FP) versus placebo. ${ }^{10}$ $\mathrm{FEV} \mathrm{V}_{1}=$ forced expiratory volume in 1 second.

( $\mathrm{N}=361) .{ }^{9}$ Patients admitted to the study had a baseline $\mathrm{FEV}_{1}$ before bronchodilation that was $25 \%$ to $70 \%$ of that predicted, an increase of $<10 \%$ of predicted $\mathrm{FEV}_{1} 30$ minutes after inhaling $400 \mu \mathrm{g}$ of albuterol, and an $\mathrm{FEV}_{\mathrm{l}} / \mathrm{FVC}$ ratio of $\leq 70 \%$ prior to the use of a bronchodilator. Asthma was ruled out as a potential confounding diagnosis.

\section{Results}

As illustrated in Figure 6, by week 2, the 3 active treatments increased pretreatment $\mathrm{FEV}_{1}$ significantly in comparison with the placebo group (fluticasone/salmeterol $P<0.001$, salmeterol $P<0.001$, fluticasone $P=0.0063$ ). The increase in $F V_{l}$ associated with combination therapy was significantly greater than that observed with either component alone. By week 52, pretreatment $\mathrm{FEV}_{1}$ in the combination group had increased by $10 \%$ compared with $2 \%$ in the other treatment groups, while falling by $3 \%$ in patients taking placebo. Combination therapy also led to statistically significant improvement in $\mathrm{FEV}_{1}$ after the use of a bronchodilator compared with the salmeterol and fluticasone treatments. As shown in Figure 6, the combination had the same effect as the individual components on PEFR in weeks 2 through 52. Finally, combination treatment produced a sustained improvement in patients' QOL measured by SGRQ. ${ }^{9}$ By week 52, patients taking fluticasone/salmeterol combination had a significantly lower total SGRQ score than patients taking either component alone or placebo.

Compared with placebo, all active treatments significantly reduced the mean number of exacerbations/patient/year as well as the mean number of exacerbations requiring treatment with oral corticosteroids. Compared with placebo, the rate of exacerbations fell by $25 \%(P<0.0001$ in the combination group), and 20\% $(P=0.0027)$ and $19 \%(P=0.0033)$ in the salmeterol and fluticasone groups, respectively. However, differences were not significantly different among active treatments.

\section{Fluticasone/Salmeterol:} In Combination Versus Each Agent Alone

\section{Trial Introduction and Method}

A 28-week randomized, double-blind, placebo-controlled, parallelgroup trial compared placebo $(\mathrm{N}=185)$, fluticasone $250 \mathrm{\mu g}$ $(\mathrm{N}=183)$, salmeterol $50 \mu \mathrm{g}(\mathrm{N}=177)$, and fluticasone/salmeterol combination inhaler 50/250 $\mu \mathrm{g}(\mathrm{N}=178)$ in patients with COPD. ${ }^{10}$ Outcomes were assessed by predose and postdose $\mathrm{FEV}_{1}$, peak flow rate, TDI, QOL, and the number of exacerbations. 


\begin{tabular}{|c|c|c|c|c|c|}
\hline & \multicolumn{5}{|c|}{ Treatment Group Comparison } \\
\hline Evaluation & FSC vs. $\mathrm{P}$ & FSC vs. F & FSC vs. S & F vs. P & $\mathrm{S}$ vs. $\mathrm{P}$ \\
\hline redose FEV 1 & $161^{*}$ & 49 & $69 *$ & $112 *$ & $92 *$ \\
\hline -hour postdose $\mathrm{FEV}_{1}$ & $214^{*}$ & $124 *$ & $74 *$ & $89 *$ & $140^{*}$ \\
\hline CDI & $0.8^{*}$ & 0.1 & 0.1 & 0.7 & $0.7^{*}$ \\
\hline CRDQ & $5.2 *$ & -0.6 & 3.2 & 5.8 & 2.0 \\
\hline CBSQ & $0.7^{*}$ & -0.1 & 0.3 & 0.8 & 0.4 \\
\hline
\end{tabular}

* $P \leq 0.048$.

Estimated differences between treatments may vary from differences between actual means due to model adjustment.

CBSQ = Chronic Bronchitis Syndrome Questionnaire; $C R D Q=$ Chronic Respiratory

Disease Questionnaire; $F=$ fluticasone propionate; $F E V_{1}=$ forced expiratory volume in 1 second; FSC = fluticasone propionate and salmeterol combined; $P=$ placebo;

$S=$ salmeterol; TDI = Transition Dyspnea Index.

\section{Results}

Morning predose $\mathrm{FEV}_{1}$ values over 24 weeks (Figure 7) show that compared with patients receiving placebo $(1 \mathrm{~mL})$ or salmeterol (91 mL), patients receiving fluticasone/salmeterol had statistically significant $(P<0.001$ and 0.012 , respectively) increases in mean $\mathrm{FEV}_{1}$ values $(165 \mathrm{~mL})$ at end point. The end point of patients in the combination therapy group was $16.6 \%$ above baseline values. Patients receiving fluticasone had a significantly greater increase in $\mathrm{FEV}_{1}(109 \mathrm{~mL}, P<0.001)$ compared with placebo and a statistically similar increase compared with the combination. As shown in Table 2, treatment with the combination also led to significantly better results $(P \leq 0.048)$ in 2-hour postdose $\mathrm{FEV}_{1}$, TDI, and QOL measures compared with placebo. Compared with its individual components, the combination caused statistically significant improvement in the predose $\mathrm{FEV}_{1}$ and 2-hour postdose $\mathrm{FEV}_{1}$ but did not show a difference in QOL or dyspnea outcomes. Both fluticasone and salmeterol, separately, performed better than placebo on $\mathrm{FEV}_{1}$ measures.

A total of 485 patients (67\%) experienced at least one adverse event during the study. More patients in the fluticasone and fluticasone/salmeterol groups experienced candidiasis (mouth and throat) than in the placebo and salmeterol groups.

There were no significant differences in the number of exacerbations or the time to first exacerbation among the treatment groups, although exacerbation rates are difficult to interpret in short-term studies.

\section{Discussion and Conclusions}

From these trials, several clear conclusions and implications emerge. First, compared with placebo and ipratropium, tiotropium is associated with greater improvement in spirometric measures, better QOL based on the SGRQ, and fewer exacerbations. Second, compared with salmeterol, tiotropium is associated with greater improvement in spirometric measures and greater improvement in clinically meaningful changes in QOL. Third, the fluticasone/salmeterol combination is associated with greater improvement in spirometric measures and dyspnea than either placebo or its individual components. Last, the fluticasone/salmeterol combination is associated with fewer exacerbations than placebo but not necessarily fewer exacerbations than either salmeterol or fluticasone. It is important to note that these studies had only a 6-month follow-up.

The Global Initiative for Chronic Obstructive Lung Disease, recommends that stage II or moderate disease should be treated with one or more long-acting bronchodilators such as tiotropium and/or salmeterol. ${ }^{11}$ Available data support the use of tiotropium since it is associated with fewer exacerbations, which are common in moderate-severe disease. Tiotropium and salmeterol should be given to relieve persistent or worsening symptoms, or regularly to prevent or reduce symptoms. Adverse reactions with these agents are pharmacologically predictable and dose-dependent and usually resolve after treatment withdrawal, especially with inhaled agents.

Patients suffering from severe disease (stage III-IV) may benefit from inhaled glucocorticoids when there are repeated exacerbations. ${ }^{11}$ The evidence shows that regular treatment with inhaled glucocorticoids is appropriate for symptomatic COPD patients with $\mathrm{FEV}_{1}<50 \%$ predicted (stage III-IV) and can reduce exacerbation frequency and improve health status. ${ }^{11,12}$ A glucocorticoid in combination with a long-acting $\beta-2$ agonist is more effective than either of the individual components administered alone. Finally, while medical treatment of COPD has advanced, failure to adhere to prescribed regimens poses a significant barrier to effective management. In one study of COPD patients using multiple medications, adherence was poor $(\sim 50 \%)$ and related to dosing intervals. ${ }^{13}$ The use of fewer daily doses is clearly desirable.

\section{DISCLOSURES}

This article is based on the proceedings of an American College of Clinical Pharmacy symposium held on October 25, 2004, in Dallas, Texas, which was supported by an educational grant from Boehringer Ingelheim Pharmaceuticals, Inc. and Pfizer, Inc. The author received an honorarium from the Postgraduate Institute for Medicine for participation in the symposium upon which this article is based. He discloses no potential bias or conflict of interest relating to this article.

\section{REFERENCES}

1. Ferguson GT, Cherniack RM. Management of chronic obstructive pulmonary disease. N Engl J Med. 1993;328:1017-22.

2. Mahler DA, Wire P, Horstman D, et al. Effectiveness of fluticasone propionate and salmeterol combination delivered via the Diskus device in the treatment of chronic obstructive pulmonary disease. Am J Respir Crit Care Med. 2002;166:1084-91.

3. Casaburi R, Mahler DA, Jones PW, et al. A long-term evaluation of oncedaily inhaled tiotropium in chronic obstructive pulmonary disease. Eur Respir J. 2002;19:217-24.

4. Gross NJ. Ipratropium bromide. N Engl J Med. 1988;319:486-94. 
5. van Noord JA, Bantje TA, Eland ME, Korducki L, Cornelissen PJ. A randomised controlled comparison of tiotropium and ipratropium in the treatment of chronic obstructive pulmonary disease. The Dutch Tiotropium Study Group. Thorax. 2000;55:289-94.

6. Vincken W, van Noord JA, Greefhorst APM, et al. Improved health outcomes in patients with COPD during 1 yr's treatment with tiotropium. Eur Respir J. 2002;9:209-16.

7. Donohue JF, van Noord JA, Bateman ED, et al. A 6-month, placebo-controlled study comparing lung function and health status changes in COPD patients treated with tiotropium or salmeterol. Chest. 2002;122:47-55.

8. Brusasco V, Hodder R, Miravitlles M, Korducki L, Towse L, Kesten S. Health outcomes following treatment for six months with once daily tiotropium compared with twice daily salmeterol in patients with COPD. Thorax. 2003;58:399-404.

9. Calverley P, Pauwels R, Vestbo J, et al. Combined salmeterol and fluticasone in the treatment of chronic obstructive pulmonary disease: a randomised controlled trial. Lancet. 2003;361:449-56.
10. Hanania NA, Darken P, Horstman D, et al. The efficacy and safety of fluticasone propionate $(250 \mu \mathrm{g}) / \mathrm{salmeterol}(50 \mu \mathrm{g})$ combined in the Diskus inhaler for the treatment of COPD. Chest. 2003;124:834-43.

11. Fabbri LM, Hurd SS. Global strategy for the diagnosis, management and prevention of COPD: 2003 update. Eur Respir J. 2003;22:1-2.

12. Global Initiative for Chronic Obstructive Lung Disease (GOLD), World Health Organization (WHO), National Heart, Lung, and Blood Institute (NHLBI). Global strategy for the diagnosis, management, and prevention of chronic obstructive pulmonary disease; 2004. Available at: http://www.goldcopd.com. Accessed May 19, 2005.

13. Dolce JJ, Crisp C, Manzella B, Richards JM, Hardin JM, Bailey WC. Medication adherence patterns in chronic obstructive pulmonary disease. Chest. 1991;99:837-41. 